\title{
33. MAGNETIC ANOMALY OBSERVATIONS IN THE EASTERN CARIBBEAN SEA
}

\author{
Thomas W. Donnelly, Department of Geology, State University of New York, Binghamton, New York
}

\section{INTRODUCTION}

The discovery of basalts and dolerites of late Cretaceous age at Sites 146, 150,151, 152, and 153 raises fundamental questions about the nature of the eastern Caribbean basement. A comparison of the inferred ages of the igneous rocks and the linear magnetic anomaly pattern (previously determined and presented orally [Donnelly, 1971], but not previously published), and further considerations of the character of the magnetic profiles themselves, suggest that the magnetic "basement" of the eastern Caribbean lies considerably beneath the igneous rocks which terminated drilling at the five sites.

\section{LINEAR MAGNETIC ANOMALIES OF THE VENEZUELAN BASIN}

A study of air-borne magnetic profiles of the Venezuelan Basin, based on profiles from Project MAGNET, reveals a pattern of linear magnetic anomalies in the Venezuelan Basin (Figures 1 and 2). Although the nine profiles considered are not optimally located, the recognition of an especially characteristic anomaly (h) in three of them led to the somewhat less convincing correlation of other anomalies further west. Anomaly i represents the transection of this anomaly pattern by another sort of anomalous basement, whose pattern is distinctly rougher (shallower sources) than that to the west. To the west, anomalies b, c, and $\mathrm{d}$ are difficult to correlate. Anomaly a is almost undoubtedly the anomaly caused by the structure (block faulting) of the Beata Ridge. Further correlation within the Colombian Basin proved totally unsatisfying.

The ages represented by the Venezuelan Basin anomaly pattern are, of course, unknown. The occurrence of middle Cretaceous to Jurassic volcanic rocks of the island-arc assemblage in the eastern Greater Antilles and Lesser Antilles suggests an age older than most of the basement presently known from the Atlantic Ocean.

\section{COMPARISON OF AIR-BORNE AND SEA MAGNETIC ANOMALY PROFILES}

The track of the Glomar Challenger in two instances ran remarkably close to previously flown air-borne magnetic lines (Figure 3). Track 230 of Project MAGNET and the ship's track approaching Site 146/149 from Site 148 run parallel for about $300 \mathrm{~km}$. Similarly, the ship's track departing Curaçao for Site 151 runs parallel to MAGNET line T025 for about $250 \mathrm{~km}$ and 0015 for nearly $500 \mathrm{~km}$. Because the principal difference in the character of these tracks is the $3 \mathrm{~km}$ additional elevation of the magnetometer for the MAGNET tracks, a comparison of the profiles (Figure 4) enables us to sense the difference in the apparent depth of the anomaly sources.
The MAGNET tracks (Figure 4) are very nearly identical, with the ship's track, and the profiles show only a few shorter wavelength, minor anomalies. If the anomalies originated in the basaltic material drilled at Site 146, the anomaly sources would then be $5 \mathrm{~km}$ and $8 \mathrm{~km}$ beneath the ship, and airplane, respectively. The similarity of the two profiles, however, suggests that the relative difference in depth to the causitive body for the two observations is much less than $3 / 8$ and that the magnetic anomalies originate at considerably greater depth. I have not attempted to model these anomalies in order to estimate the depth of the anomalous source, but it may be one or several kilometers deeper than the dolerite of Site 146.

The ship's magnetic profiles for the southwestern Venezuelan Basin (Figure 5) are greatly different from the air-borne profiles, showing a much stronger component of shorter wave-length fluctuations. A comparison of the anomaly traces with the sea-bottom topography (lowest trace of Figure 5), however, is puzzling; there is little discernible correlation between the bottom (and subbottom) configuration and the magnetic anomalies. At the crest of the Beata Ridge (near point C) the water shoals to less than half the depth in the basin between points $C$ and A. However, the magnetic anomaly pattern does not appear to reflect this marked change in depth.

The shorter wave-length fluctuations in the ship profiles (Figure 5) imply a shallow source for these magnetic anomalies. However, the insensitivity of the magnetic anomaly profile to the shoaling of the Beata Ridge implies that these sources are not uniformly distributed or at a constant distance from the sediment surface. Especially puzzling is the fact that the MAGNET 0015 track becomes relatively smooth over the Beata Ridge. Tentatively it may be concluded that the anomalies could arise from subbottom areas of magnetic contrast rather than from bottom topography.

An attempt was made to determine whether the basalt drilled at Site 151 could be responsible for the magnetic anomalies seen at the ridge. The susceptibility and remanent magnetization of the two samples of Site 151 basalt were measured by Lowrie and Opdyke (this volume). Assuming these samples are representative of the map of basalt on the ridge, a model was constructed for a tabular body of varying thickness whose upper surface conformed to the sharply defined reflector at the crest of the ridge; however, this surface configuration is difficult to determine because of the vertical exaggeration of the air-gun profile. Even for a very thick flow with the sharpest changes in slope allowable from this profile, the theoretical anomaly is very small. If the two samples measured by Lowrie and Opdyke are representative of the flow at this site, then the susceptibility and remanent magnetization are too weak to produce an appreciable anomaly even with considerable topography. 


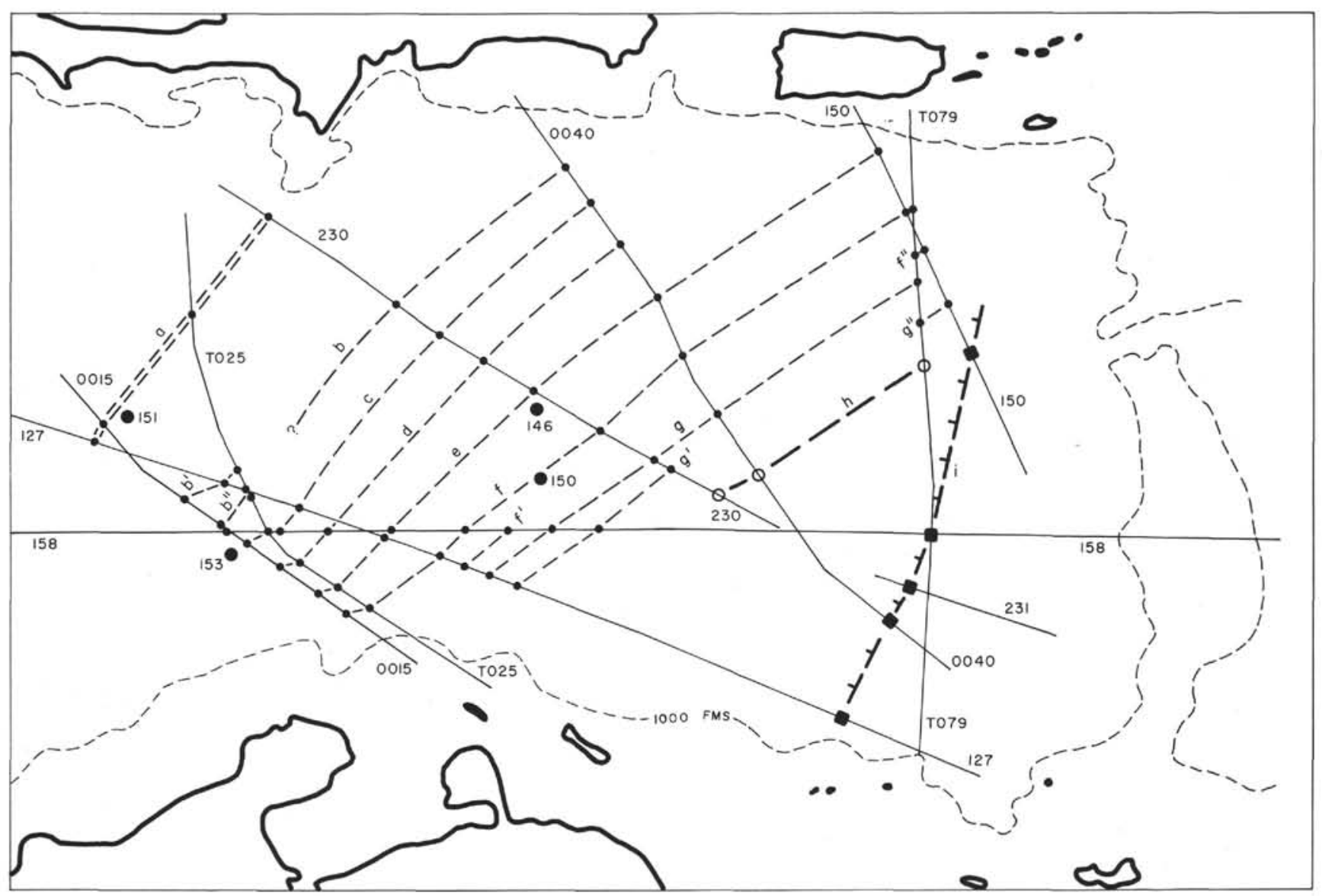

Figure 1. Map of the Venezuelan Basin showing linear magnetic anomalies based on air-borne survey (Project MAGNET). Lines of distinctive character represent especially easily identified anomalies.

Fox et al. (1970) reported on numerous dredged samples of basalt from the Beata Ridge. One of these samples was radiometrically dated (feldspars and whole rock) at 64 to 65 m.y., which is distinctly younger than the basalt at Site 151 (Santonian or older). Fox (personal communication) has provided data that show that the susceptibilities of these basalts average about five times as high as the Site 151 basalt. The remanent magnetizations are low, but submarine weathering could account for this. Fox et al. basalts are also different petrographically from the 151 basalt: several samples contain olivine or pseudomorphs after olivine, and this mineral has not been found in any of the older Leg 15 basalts or dolerites. The dredged basalts of Fox et al., might represent the eruption of linear intrusive bodies associated with block faulting of the Beata Ridge. These bodies might correspond to characteristic subbottom reflector highs off the Beata Ridge both east and west of Site 151 (Figures 5 and 6), all of which have prominent magnetic anomalies. The block faulting of the ridge, then, would be dated as at least latest Cretaceous. The remaining short-wavelength anomalies between points $\mathrm{A}$ and $\mathrm{C}$ of Figure 5, then, might correspond to similar rather minor intrusives, whose absence from the air-gun records would not be remarkable.

The contrast between the magnetic characteristics of the central and the southwestern Venezuelan Basin appears to be caused by the presence in the latter place of discrete, shallow sources of the anomalies. The increase in block faulting towards the west and southwest, and the abundance of basalts dredged along one of the most prominent scarps-the western scarp of the Beata Ridge-suggests that the more western area may be shot through with basaltic intrusive bodies.

\section{MAGNETIC CHARACTER OF SITE 145}

Site 145 , which was not drilled because of mechanical problems, was located on a distinctive knoll in the north-central Venezuelan Basin. A magnetic profile made during the site survey is shown in Figure 7 . The distinctive anomaly associated with this knoll suggests that the feature represents an igneous rock. The character of this anomalya very large negative anomaly located north of a smaller positive anomaly-could not reasonably be caused by a body whose magnetization was wholly induced. Very probably this body has a relatively large remanent magnetization, with a magnetization vector inclination more nearly horizontal than the present-day field inclination in the Caribbean. This type of anomaly, which is characteristic of bodies elsewhere in the Caribbean (Donnelly, 1971), apparently reinforces Lowrie and Opdyke's conclusion (this volume) that much of the Cretaceous magmatism occurred at a distinctly lower magnetic latitude than exists today, 


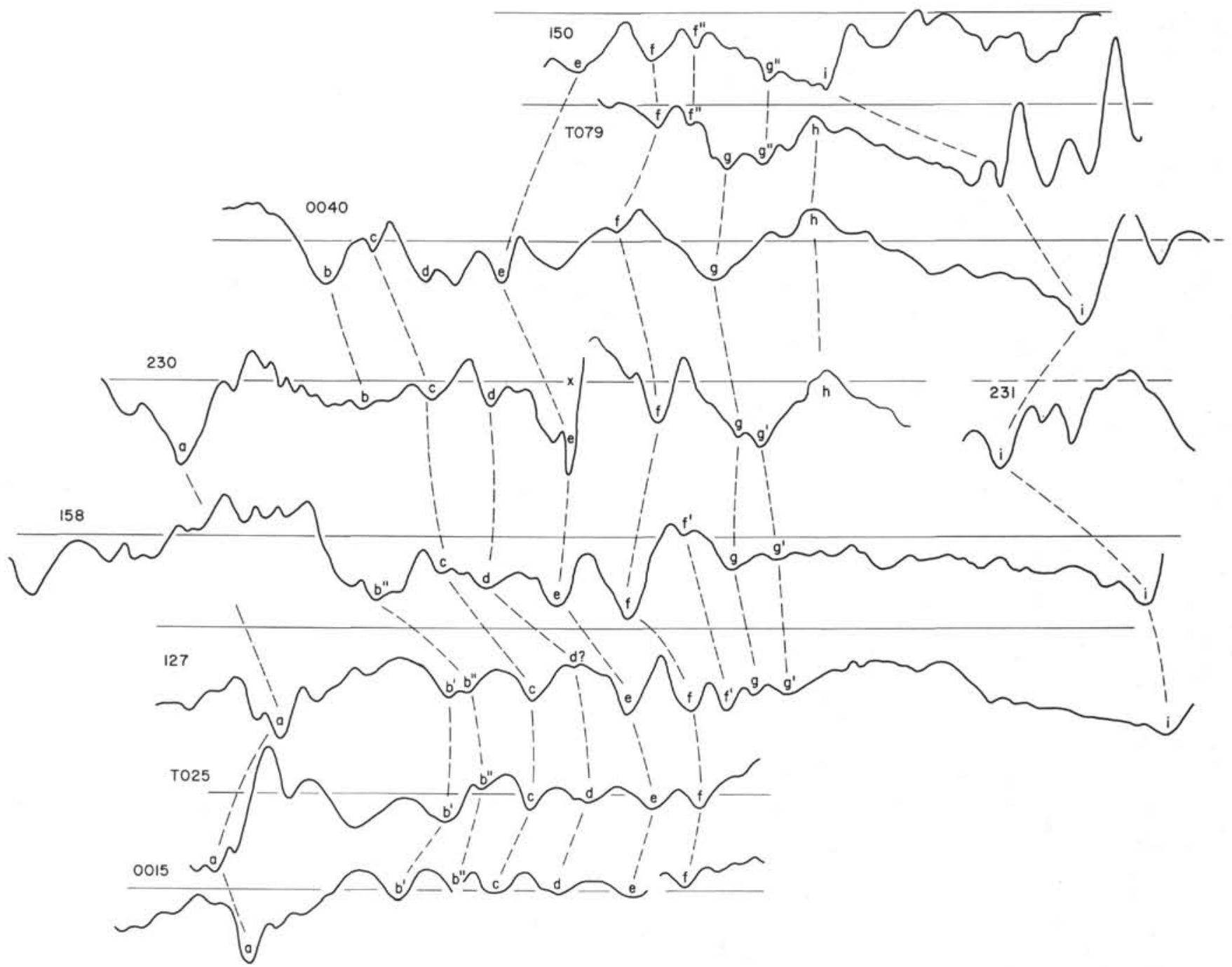

Figure 2. Airborne magnetic profiles upon which map (Figure 1) was based. Base values arbitrary. " $X$ " on profile 230 near anomaly $E$ is close to Site 146.

even with a geocentric pole. (See Raff, this volume for detailed discussion of Site 145 magnetic anomaly.)

\section{ACKNOWLEDGMENTS}

G. Lorentzen and H. Stockard provided microfilms for the project MAGNET profiles. Olga Kurty drafted several of the figures. Christine Powell assisted in several aspects of the project MAGNET study.

\section{REFERENCES}

Donnelly, T. W., 1971. A preliminary analysis of aeromagnetic profiles in the Gulf of Mexico and Caribbean areas (abs.) Trans. Fifth Caribbean Geol. Conf., St. Thomas, July 1968. Geol. Bull., Queen's College Press. 9.

Fox, P. J., Ruddiman, W. F., Ryan, W. B. F. and Heezen, B. C., 1970. The geology of the Caribbean crust, I: Beata Ridge. Tectonophysics. 10, 495 . 

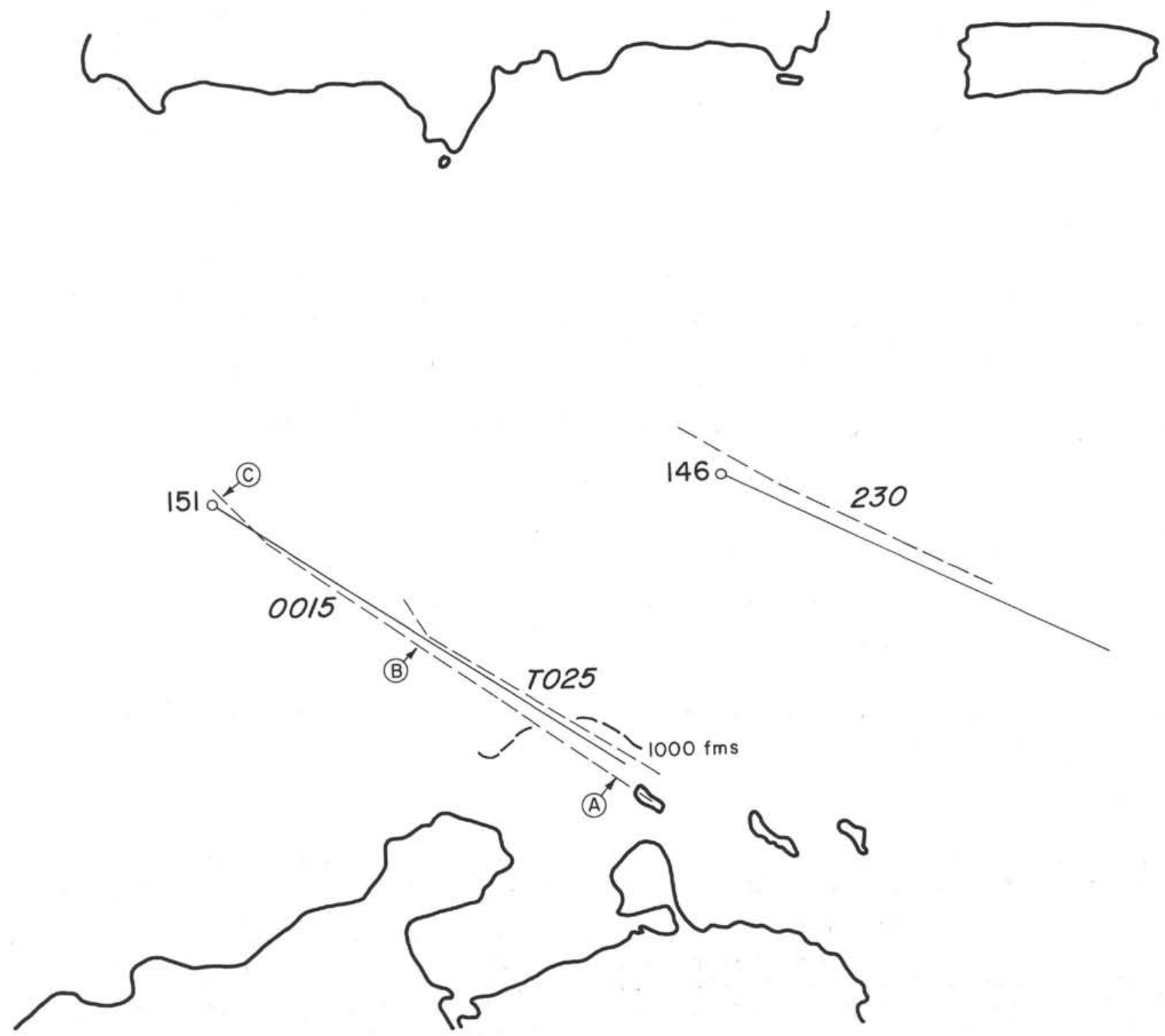

Figure 3. Map showing airborne tracks (Project MAGNET, lines 230, T025, and 0015) (dashed lines), and track of the Glomar Challenger (solid line). Points $A, B$, and C are simply reference points. 

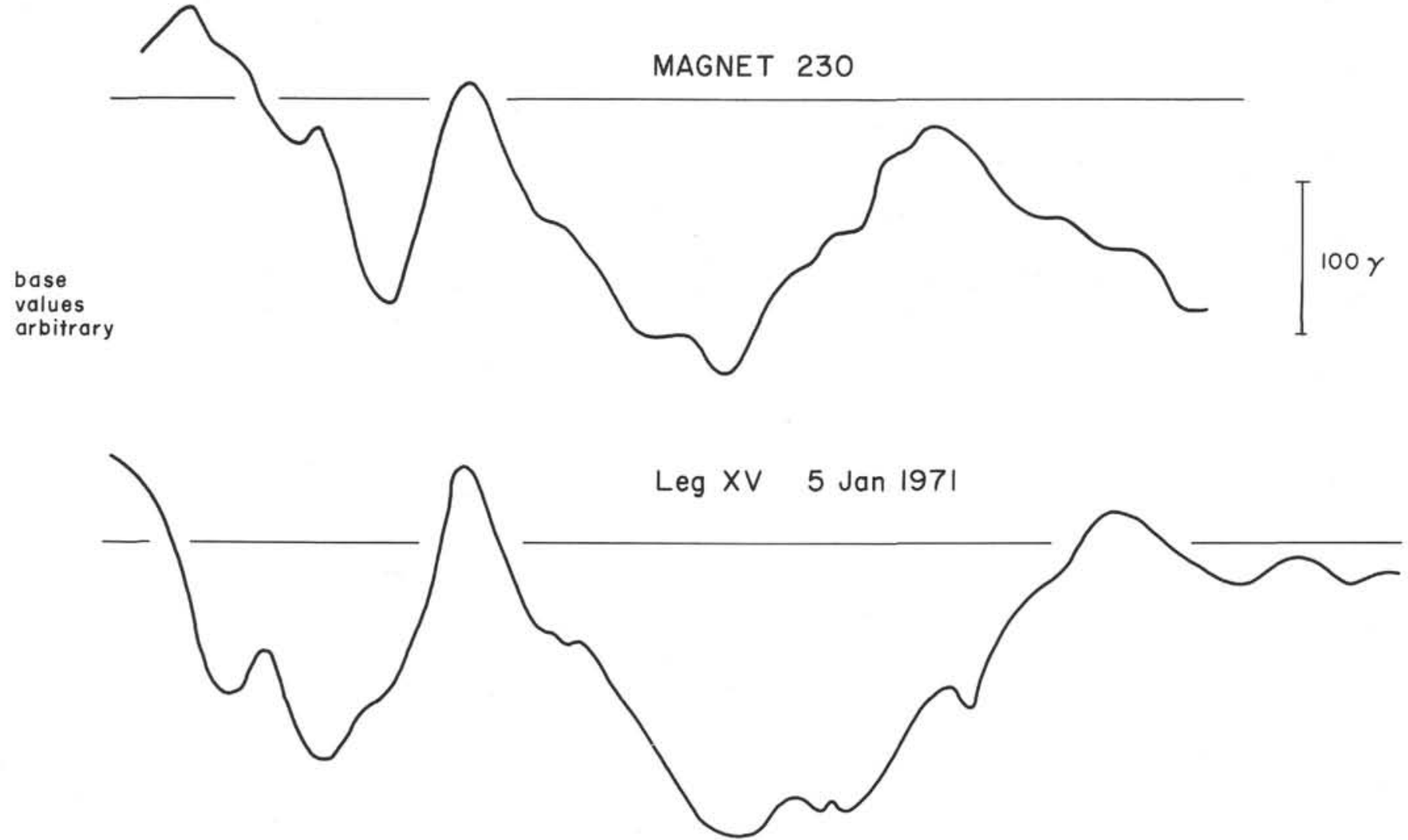

Figure 4. Comparison of air-borne and sea magnetic profiles of central Venezuelan Basin. Location shown on Figure 3. Note that the horizontal scales are not identical. 


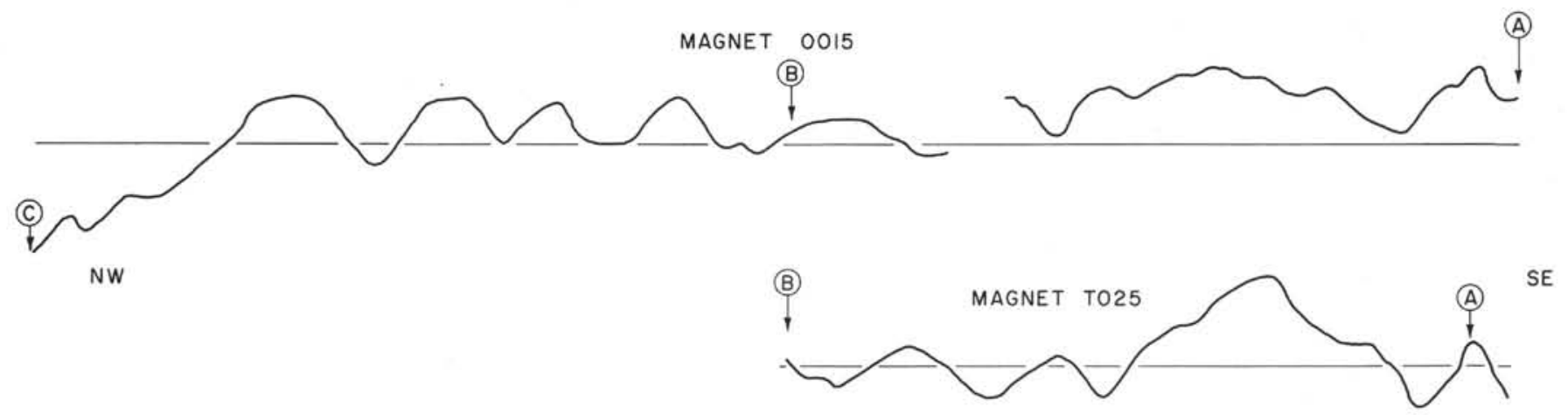

base values arbitrary
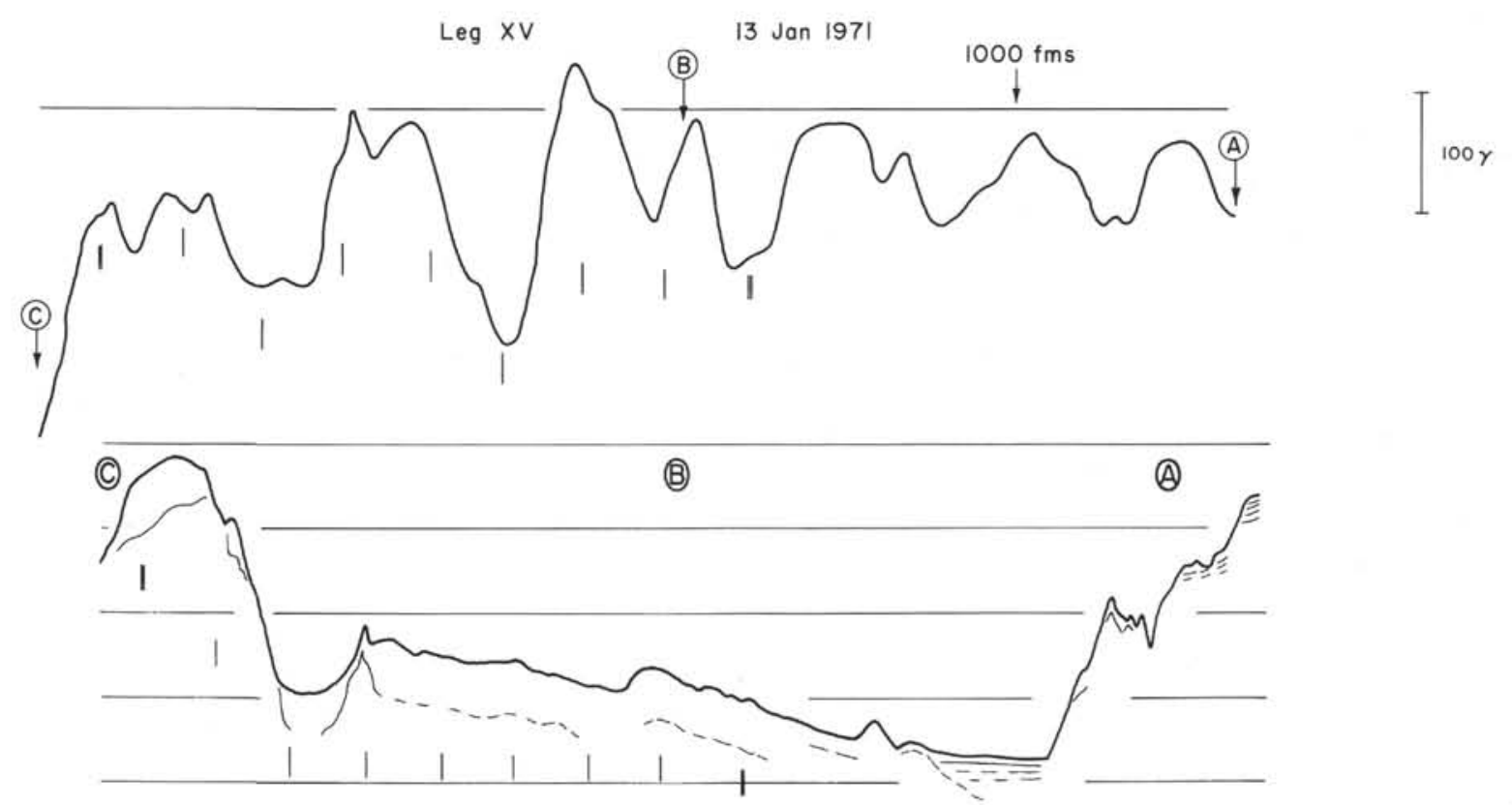

Figure 5. Comparison of air-borne ad sea magnetic and bottom and subottom profiles, of southwestern Venezuelan Basin, approaching Site 151. Location shown on Figure 3. Horizontal lines are 1 second marks on air-gun record. Vertical lines are hour marks, which are correlated in the two profiles by two double-lined marks. 


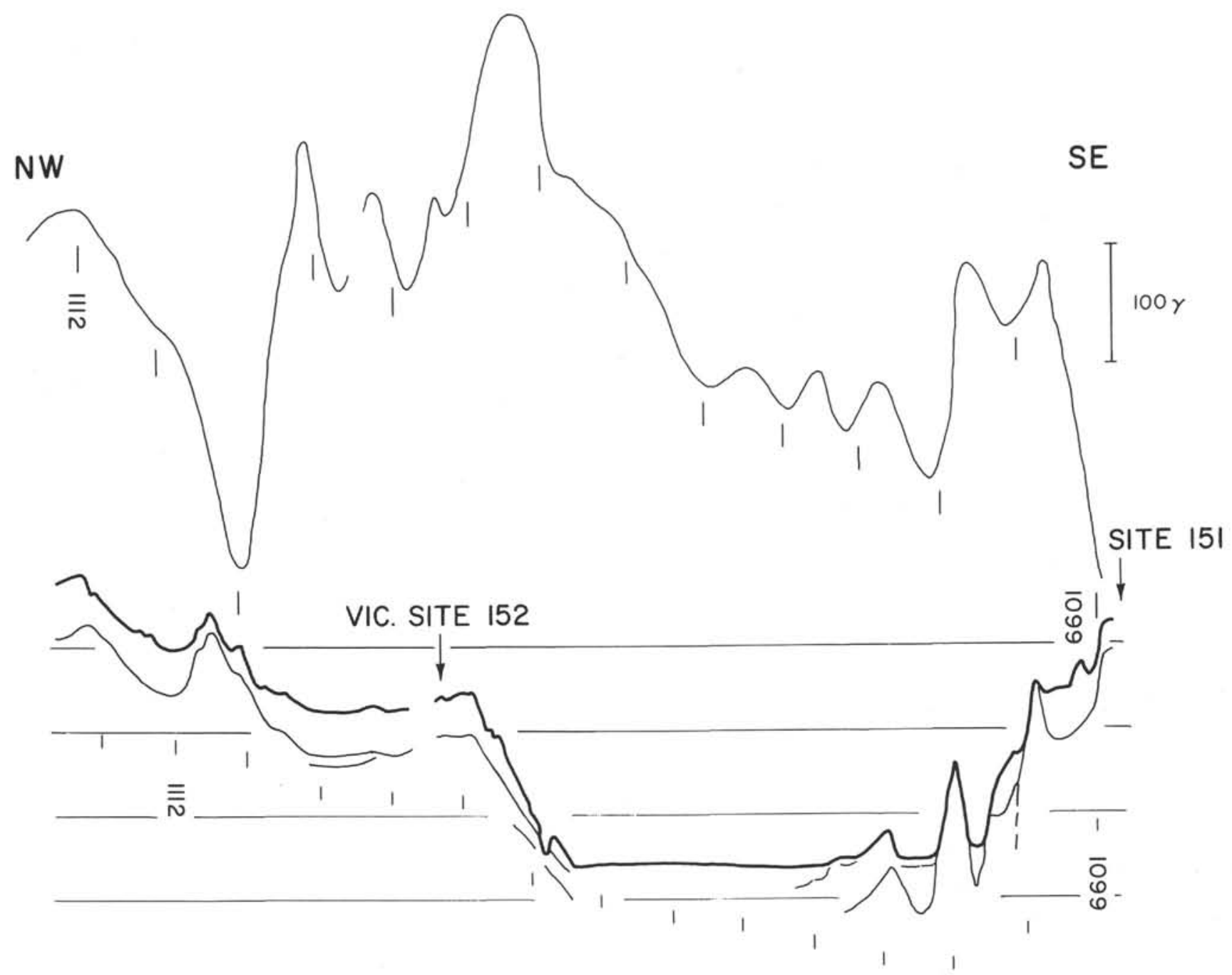

Figure 6. Magnetic profile and air-gun profile of Site 152. Explanation as for Figure 5. Hour marks correlated by numbers showing elapsed hours since beginning of leg. The gap in the record just $N W$ of Site 152 represents a course change.

N

$5 \operatorname{Dec} 1970$

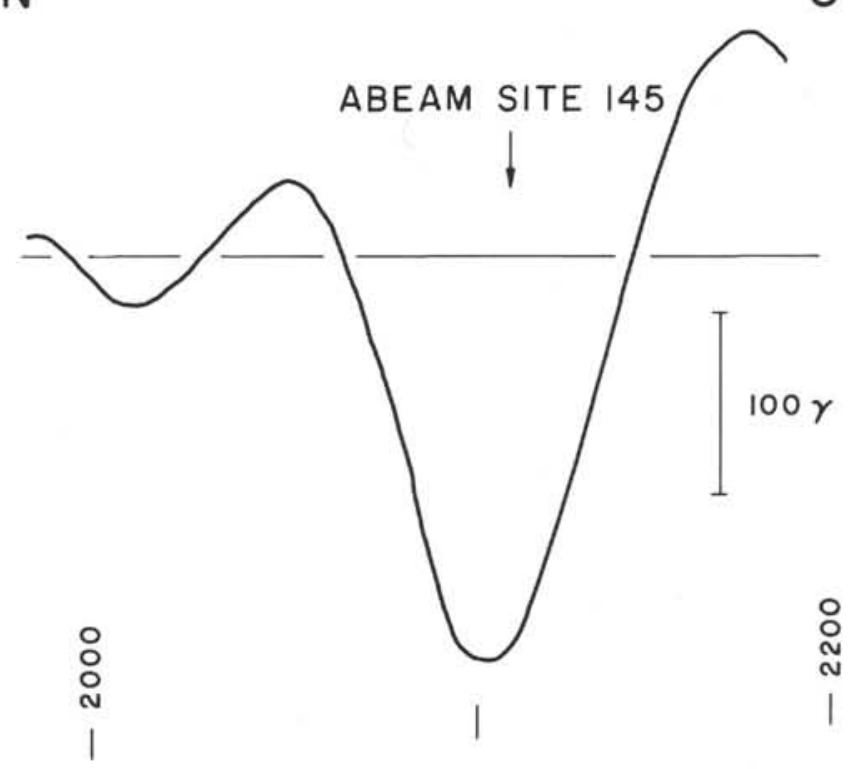

Figure 7. North-south magnetic traverse past Site 145, showing distinctive magnetic anomaly associated with the site. 